\section{Endoscopic treatment of a completely obstructed ileorectal anastomosis}
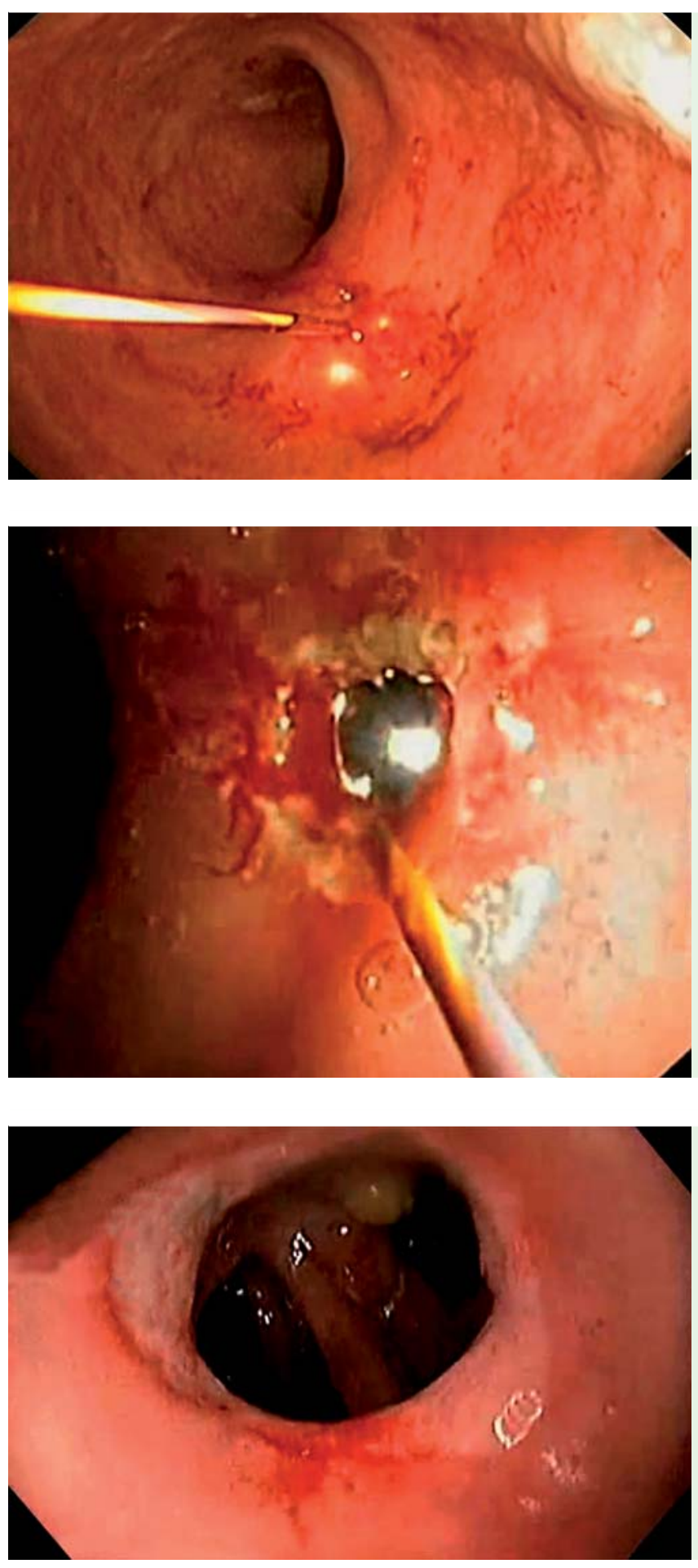

Fig. 1 Endoscopic treatment of a completely obstructed ileorectal anastomosis. A guidewire is passed through a 19-gauge needle.

Fig. 2 Endoscopic view of the second endoscope after balloon dilation.

Fig. 3 Endoscopic aspect of the anastomosis after stent removal.
Complete anastomotic obstruction secondary to a benign disease is rare, with only a few reports of endoscopic management in the literature [1-3]. We describe a case of the successful endoscopic management of a completely obstructed ileorectal anastomosis with the use of an endoscopic rendezvous technique. A 55-year-old man was admitted in September of 2009 for severe alcoholic pancreatitis. Organ necrosis developed, so that subtotal colectomy and lateral ileostomy were required. In May 2010, an ileorectal anastomosis was established, and ileostomy closure was postponed. After 3 months, the patient underwent a rectoscopy, which revealed complete obstruction of the anastomosis. At the same time, a second operator conducted an endoscopic procedure through the ileostomy. Transillumination was obtained from both sides. Fluoroscopy showed that the two endoscope tips were almost in contact with each other. We punctured the upper side of the anastomosis with a 19-gauge needle (Cook Endoscopy, Winston-Salem, North Carolina, USA) and passed a Metro II guidewire (Cook Endoscopy) through the needle ( $\bullet$ Fig.1). A 10-Fr cystotome (Cook Endoscopy) was then passed from below upward over the guidewire, and dilation with a 10-mm Quantum Maverick balloon (Boston Scientific, Natick, Massachusetts, USA) was carried out ( Fig. 2), followed by the placement of a fully covered self-expandable Wallstent (Boston Scientific) measuring $80 \times 10 \mathrm{~cm}$ ( Video 1 ). After 1 week, the stent was removed ( $\bullet$ Fig.3), and the new orifice was further dilated to $15 \mathrm{~mm}$. At 6 months after the procedure, the patient's bowel habits had returned to normal. Complete obstruction of an anastomosis presents a particular challenge because it requires a real recanalization. The technique of rendezvous was first proposed in the management of complex esophageal strictures [4]. The use of this therapeutic approach to treat complete obstruction of a colorectal anastomosis under fluoroscopic control [5], endoscopic ultrasound [6], or computed tomography [7] has been reported. Our case is, to our knowledge, the first one in which an ileorectal anastomosis was treated.

\section{Video 1}

Video showing transillumination of the obstructed anastomosis, puncture with a 19-gauge needle, passage of the guidewire, passage of the cystotome, balloon dilation, and stent deployment. The final result is a functional anastomosis. 


\section{Endoscopy_UCTN_Code_TTT_1AQ_2AF}

\section{Competing interests: None}

\section{Najib Al Ghossaini ${ }^{1}$, Vincent Maunoury $^{2}$, Richard Delcenserie ${ }^{3}$, Philippe Bulois ${ }^{4}$}

1 Saint Omer Hospital, Gastroenterology Department, Saint Omer, France

2 Lille University Hospital, Gastroenterology Department, Lille, France

${ }^{3}$ Amiens University Hospital, Gastroenterology Department, Amiens, France

${ }^{4}$ La Louvière Private Hospital, Générale de Santé, Lille, France

\section{References}

1 Mukai M, Kishima K, Iizuka $S$ et al. Endoscopic hook knife cutting before balloon dilatation of a severe anastomotic stricture after rectal cancer resection. Endoscopy 2009; 41: E193-E194

2 Repici A, Pagano N, Romeo F et al. Endoscopic treatment of a complete colonic anastomotic stricture by the rendez-vous technique. Dig Liv Dis 2010; 42 (Suppl. 02): 98 -S99

3 Curcio G, Spada $M$, di Francesco $F$ et al. Completely obstructed colorectal anastomosis: a new nonelectrosurgical endoscopic approach before balloon dilatation. World J Gastroenterol 2010; 16: 4751-4754

4 Bueno R, Swanson SJ, Jaklitsch MT et al. Combined antegrade and retrograde dilation: a new endoscopic technique in the management of complex esophageal stricture. Gastrointest Endosc 2001; 54: 368 - 372

5 Kaushik N, Rubin J, McGrath K. Treatment of benign complete colonic anastomotic obstruction by using an endoscopic rendezvous technique. Gastrointest Endosc 2006; 4: $727-730$

6 De Lusong MA, Shah JN, Soetikno $R$ et al. Treatment of a completely obstructed co- lonic anastomotic stricture by using a prototype forward-array echoendoscope and facilitated by SpyGlass (with videos). Gastrointest Endosc 2008; 68: 988 - 992

7 Albertsmeier M, Rittler P, Hoffmann RT et al. Treatment of a completely obstructed colonic anastomosis using a CT-guided endoscopic rendezvous technique. Endoscopy 2011; 43 (Suppl. 02): E5 -E6

\section{Bibliography}

DOI http://dx.doi.org/

10.1055/s-0034-1390753

Endoscopy 2014; 46: E609-E610

(c) Georg Thieme Verlag KG

Stuttgart · New York

ISSN 0013-726X

\section{Corresponding author}

Philippe Bulois, MD

20 rue du Ballon

F-59000 Lille

France

Fax: +33320576947

philippebulois@yahoo.fr 